\title{
EN LOS ARRABALES DE LA CIVILIZACIÓN
}

La otra ciudad según los higienistas en la Lima dél novecientos

\section{Gabriel Ramón}

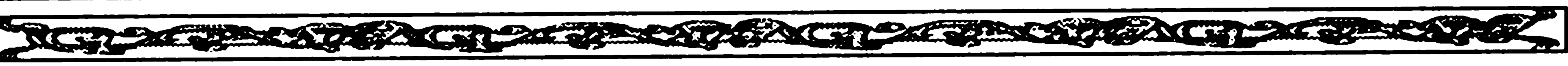

Sólo después de saber cómo y dónde vive el bajo pueblo - la multitud que constituye la gran masa del elemento trabajadores que se pueden formular en nombre de la higiene, de la moral y de la caridad los preceptos encaminados a mejorar su anómala situación, a la que contribuyen todos: las autoridades con su indiferencia, los propietarios con su avaricia y el pueblo con su desidia. Basurco y Avendaño, 1907

LA PALABRA ARRABAL PROVIENE del hispanoárabe del siglo XIl y define al barrio situado en los confines de una población. En su gentilicio (arrabalero) adquiere una connotación sumamente peyorativa. Civilización es a la vez anterior (por su raíz) y posterior, porque en su acepción plena comenzó a usarse recién en el siglo XVIII, aludiendo tanto a la acción y efecto de civilizar como al "estado social de un pueblo". Ambos términos comparten una sutil ambivalencia, siendo tanto políticos como espaciales. Su correspondencia hace imprescindible considerar uno para comprender al otro y en atención a ello se pretende caracterizar a la civilización limeña del no- 


\section{GABRIEL RAMÓN}

vecientos a partir de su acción y reacción ante los ocupantes del arrabal. Se tomarán los límites como parte esencial de la definición.

En este contexto, se discutirá enseguida una coyuntura precisa: el "descubrimiento" que los representantes de la ciudad oficial limeña realizaron del domicilio de los pobres, de aquel "antro infecto" hasta entonces ignoto y ajeno. Con tal objetivo se aborda en detalle un acontecimiento particularmente significativo, que permite entender la agitada situación de los callejones y las casas con cuartos de vecindad a inicios de siglo. Las más reputadas autoridades de la ciudad oficial (un médico y un ingeniero), portadoras de los instrumentos de la "civilización", penetraron en los lugares más "putrefactos", en la otra Lima, con la finalidad de advertir acerca del peligro inminente que significaban para la ciudad decente. ¿Por qué estos espacios tradicionalmente desatendidos por las autoridades se situaron de pronto en el centro de su preocupación? ¿Por qué determinados modos de vida privada se convirtieron en infracciones?

Los antecedentes inmediatos del asunto aquí tratado se remontan a fines del siglo XVIII, cuando, a través del proyecto borbónico, se dejan sentir en Lima los primeros vientos del higienismo, considerado como una estrategia médica de incidencia decisiva en la planificación de la forma urbana ${ }^{1}$. En los albores de la república serán retomados algunos lineamientos de la inconclusa empresa borbónica y la paulatina instauración del nuevo Estado será realizada conjuntamente con la intervención oficial en el espacio público limeño ${ }^{2}$. En las postrimerías del siglo XIX la

${ }^{1}$ Clement, 1983.

2 Para esta coyuntura existen trabajos sobre los más diversos aspectos de las ciudades hispanoamericanas. En el caso de Lima se trata de un momento de intensas modificaciones urbanísticas. La ciudad es dividida en cuarteles y distritos para brindar un "cómodo servicio de policía", se reforman las plazas y parques para utilizarlos como espacios cívico-pedagógicos (Majluf, 1994), se reorganiza la nomenclatura urbana (Ramón, 1997), al tiempo que se instaura un nuevo régimen disciplinario que tiene en el Manicomio (1859) (Ruiz, 1994) y el Panóptico (1862)(Méndez, 1987; AGUIRRE, 1995) sus principales emblemas. 


\section{EN LOS ARRABALES DE LA CIVILIZACIÓN}

reconstituida elite civilista de la posguerra del Pacífico (1879-83) conseguirá reformular radicalmente las reglas del juego urbano. Entonces se instituirá una nueva estrategia política: la intervención oficial al interior de las viviendas populares con el aval de los preceptos higienistas. El ingreso coordinado a este territorio prácticamente desconocido coincide con una transformación mayor en la sociedad limeña -el comienzo de la denominada República Aristocrática (1895-1919)- y a la vez contribuye a caracterizarla desde un ámbito virtualmente inexplorado ${ }^{3}$.

El corpus documental básico para esta investigación lo constituye la literatura producida por las autoridades sanitarias limeñas entre fines del siglo XIX e inicios del siguiente. Tales escritos revelan la constitución de una nueva modalidad de conocimiento y evidencian la utilidad que el higienismo tuvo en la planificación de la ciudad. Enseguida se pretende auscultar las relaciones existentes entre proyecto político y uso del espacio. En tal sentido se considera que el nuevo juego de fuerzas que trajo consigo la República Aristocrática, como, por ejemplo, la incorporación restrictiva de las masas en la práctica política, implicaba la atención oficial a determinados recintos, específicamente aquellos que albergaban a los miserables de la urbe. Pero estas prácticas no podían realizarse en el vacío retórico, sino que requerían y provocaban un tipo de discurso que justificase tales procedimientos. Asimismo, la modificación -proyectada y/u obtenida- de los usos sociales del espacio (la redistribución de la población en la ciudad) dice mucho de los móviles políticos de la ciudad oficial.

${ }^{3}$ Como en las señaladas coyunturas de fines del siglo XVIII e inicios del siglo XIX, se observa nuevamente una especie de proceso sincrónico con notables semejanzas en las diferentes capitales del continente (Cf. Romero, 1976; Gutiérrez, 1983). No sólo se trata de una tradición urbana compartida, sino además de una situación semejante en el sistema mundial. A pesar de las obvias diferencias, desde el Santiago de Vicuña Mackenna (Ramón, 1992), hasta el Río de Janeiro de Barata Ribeiro y Pereira Passos (Chalhoub, 1996) pasando por las modificaciones ocurridas en Montevideo (Barran, 1994, 1995) y México (Hernándes, 1994) las ciudades parecen ser casos específicos de un proyecto mayor, compartiendo parafernalia y estrategia. Lima no fue una excepción. 


\section{LA EPOPEYA HIGIENISTA}

Considerando a la ciudad como un gran tablero, puede decirse que el primer movimiento estratégico que el incipiente higienismo realizó en Lima fue el traslado del cementerio a extramuros (1808). Tradicionalmente, los óbitos habían sido enterrados en las inmediaciones de las iglesias, pero la llegada a Hispanoamérica de los preceptos ilustrados permitió que las elites intelectuales auxiliaran al Estado a concluir con tal empeño. Esta novedad provocó fricciones entre el aún poderoso clero, que deseaba mantener sus fueros $e$ ingresos, y los ilustrados criollos que, desde el Mercurio Peruano, reclamaban por la contaminación provocada por esta arcaica costumbre, invocando, además, razones históricas: las civilizaciones clásicas enterraban a sus muertos lejos de las poblaciones. Bajo los mismos preceptos se renovó la iluminación pública, se controló la circulación de animales callejeros y de miserables, encerrando a los vagabundos e incrementando las rondas policiales ${ }^{4}$.

Los desórdenes provocados por las guerras de la independencia provocaron la ruralización de las ciudades hispanoamericanas y desarticularon la maquinaria estatal. Como consecuencia de esto, la institución médica decaerá y, luego del periodo áureo de las postrimerías coloniales, en el cual contaba con figuras de renombre como Gabriel Moreno o Hipólito Unanue, enfrentará una época de conmoción. El panorama mejorará a mediados de siglo con la reorganización de los estudios médicos en San Fernando (1842) y la Reforma Universitaria (1861), que significó la centralización en San Marcos de las diversas facultades de la ciudad, entre ellas la de medicina. En la década siguiente Lima ya contaba con 142 médicos $^{5}$.

Pero como mejor se puede sondear la institucionalización del cuerpo médico es a partir de las reacciones ante tres coyunturas epidémicas precisas. Desde inicios del siglo XIX Lima afrontó una serie de epidemias, especialmente de viruela (1801, 1802,

${ }^{4}$ Puede verse Clement, 1983; Archila, 1983.

${ }^{5}$ Lastres, 1951, p. 323. 


\section{EN LOS ARRABALES DE LA CIVILIZACIÓN}

$1806,1814,1826,1828,1832,1838,1847,1852,1859,1863$, $1873,1885,1891.1896,1902)$ y de fiebre amarilla $(1851-5,1867-$ $9,1884)$. A pesar de la incipiente presencia de recursos médicos durante la primera parte del siglo, como, por ejemplo, la vacuna antivariólica -introducida a gran escala por la Expedición Balmis a inicios de siglo por todo el continente americano-, los centros urbanos se hallaban prácticamente impotentes ante estas epidemias que arrasaban con porciones considerables de su población ${ }^{6}$.

La primera coyuntura data de 1837, cuando se presentó un rumor de cólera. La ausencia de medios con los cuales afrontar la epidemia hizo que las autoridades se limitaran a recomendar el mantenimiento de un "perfecto estado de limpieza". Se trataba de recuperar un orden perdido. Ante la ausencia de organizaciones médicas específicas, el Consejo de gobierno determinó entonces que los agentes de policía volvieran a asumir la vigilancia de la ciudad, cuidando que las fuentes y acequias se mantuviesen corrientes; las calles, plazas y lugares públicos aseados; no se vendieran alimentos de mala calidad y se alejaran de los centros poblados "todas las causas de corrupción cuyos miasmas infestan el aire, y son el vehículo de las pestes"?

La irrupción de la fiebre amarilla (1852-4) enmarca la segunda coyuntura. En la llegada de esta epidemia a Lima ya se registra la existencia de instituciones como la Junta Suprema de Sanidad, que recurre a estrategias como el control portuario (impidiendo el ingreso de buques contaminados), el aislamiento (confinando a los enfermos en lazaretos o lugares apartados), además de la ya señalada higiene doméstica. A pesar de que las autoridades continuaban impotentes ante el mal, ya había un cuerpo institucional que recomendaba medidas destinadas a evitar mayores niveles de contagio ${ }^{8}$.

- Cuán precarios serían los recursos científicos y logísticos del Estado que. incluso en fecha tan tardía como 1868, ante una epidemia de fiebre amarilla que provocó aproximadamente 4.445 muertos (4.3\% de la población), el arzobispo limeño decretó la salida de la procesión del Señor de los Milagros como paliativo.

${ }^{7}$ Archivo Histórico de la Municipalidad de Lima (AHML). Intendencia de Policía. Prefectura, 1837, cuaderno 1, documento 15.

'Eyzaguirre, 1906d. 


\section{GABRIEL RAMÓN}

La última coyuntura data de 1867-8, cuando la fiebre amarilla volvió a hacer estragos en la ciudad. El Ministerio de Justicia, Culto, Instrucción, Beneficencia y Gobierno coordinó las actividades con las autoridades municipales (Intendencia Municipal e Intendencia de Policía) y la Beneficencia Pública, asumiendo los dictados de las autoridades médicas (Facultad de Medicina de San Fernando, Sociedad Médica y Juntas de Sanidad). En esta ocasión también se recurrió a las estrategias utilizadas en la epidemia precedente (control portuario, aislamiento, etc.), pero se dio un notable cambio cuantitativo. Además de los tres hospitales tradicionales (San Andrés, San Bartolomé y Santa Ana), se implementaron dos lazaretos en las afueras de la ciudad y el número de personas internadas aumentó notablemente. También se dio una alteración cualitativa: las autoridades determinaron la necesidad de poner en práctica las visitas domiciliarias para atender algunos enfermos y anular cualquier foco infeccioso 9 . Persiguiendo la solución a la catástrofe epidémica, las autoridades dieron así el primer paso hacia el interior dél recinto doméstico, debiendo aguardar a la epidemia de peste bubónica (1903) para franquearlo plenamente ${ }^{10}$.

Recurriendo a la analogía con que se inició esta sección, podría decirse que el movimiento culminante del higienismo en la regulación del orden urbano se dio en 1903. Para entonces las autoridades sanitarias ya contaban con la autoridad suficiente para revisar el estado de salubridad de los recintos eclesiásticos. El más poderoso propietario de inmuebles urbanos durante el periodo colonial debía tolerar ahora la incursión de las autoridades médicas en su propio territorio ${ }^{11}$.

\section{LAS VISITAS DOMICILIARIAS Y EL SERVICIO MÉDICO URBANO}

Entre las medidas sanitarias de más nítidas repercusiones espaciales en la lucha contra las epidemias destacan las visitas domicilia-

${ }^{9}$ Ibid.

${ }^{10}$ Sobre las estrategias médicas utilizadas durante la epidemia de peste bubónica véase Cueto, 1991.

${ }^{11}$ Memoria de la Municipalidad de Lima, 1903, pp. I-XI. 
rias $^{12}$. Habiendo sido ocasionalmente utilizadas desde mediados del siglo XIX, sólo fueron adoptadas de forma oficial en las últimas décadas del siglo. La primera mención republicana de esta estrategia de intervención médica está registrada durante la epidemia de fiebre amarilla de 1853, cuando, en su sesión del 9 de febrero, la Junta de Sanidad, además de reconocer su impotencia ante el mal, recomendó el establecimiento de un lazareto y acordó que en cada cuartel se hicieran visitas domiciliarias de orden higiénico a cargo de médicos y vecinos notables ${ }^{13}$. Ya en el ápice de la epidemia de fiebre amarilla, el 25 de abril de 1868, una resolución suprema determinó la realización de visitas domiciliarias, especialmente en los callejones, solares y otros tipos de habitaciones ocupadas por la "clase menesterosa". Además de administrar los medicamentos necesarios, durante estas visitas se dictaban las providencias indispensables para mejorar las condiciones higiénicas y se realizaba la desinfección inmediata, emitiendo también un detallado informe de los pacientes de cada domicilio ${ }^{14}$.

Luego que amainó la epidemia de 1868 , se mantuvo la estrategia. En septiembre, una resolución suprema determinó la reorganización del servicio médico domiciliario, que había sido suspendido en junio ${ }^{15}$. En 1884 -cuando aparecieron nuevamente algunos casos de tifus icteroides- la municipalidad restableció las visitas domiciliarias y al año siguiente la Comisión de Epidemia de la Academia Nacional de Medicina -compuesta por los especialistas más notables- recomendó la vigilancia y reforma de las condiciones higiénicas de los domicilios populares ${ }^{16}$.

${ }^{12}$ La estrategia de intervención oficial en los domicilios es típica del siglo $\mathrm{XIX}$, sin embargo tiene una historia más remota. En esta ocasión la investigación se restringió al periodo republicano, pero se desconoce lo sucedido en el periodo colonial. Para los antecedentes de esta estrategia sanitaria en la Europa del siglo XVII puede consultarse, entre otros, el libro testimonial de Daniel Defoe, A journal of the plague year (1722), sobre la peste bubónica que azotó Londres en 1665, y las referencias incluidas en el trabajo de Cipolla, 1993, pp.132-142 sobre las epidemias en Italia del mismo periodo.

${ }^{13}$ Eyzaguirre, 1906d, p. 25.

14 Eyzaguirre, 1906d, pp. 62-3.

15 Eyzaguirre, 1906d, p. 73.

${ }^{16}$ Ibid., 1906d, p. 88. 


\section{GABRIEL RAMÓN}

Para inicios del siglo XX ya estaba institucionalizado una especie de servicio médico urbano que resultó de la formalización de las estrategias aplicadas en las coyunturas epidémicas. Cada cuartel de la ciudad contaba con un especialista que tenía las siguientes funciones básicas: a) atender a los enfermos en su consultorio; b) hacer visitas domiciliarias y de establecimientos públicos; c) emitir certificados-de salud (de personas y establecimientos), de defunción, etc.; d) ejercer la higienización y la desinfección de los lugares que lo necesitasen; e) vacuna; f) registrar el estado higiénico de su jurisdicción y emitir un informe sobre el particular al inspector de Higiene de la municipalidad ${ }^{17}$.

En sus informes, los médicos de cuartel realizaban un resumen de sus actividades. Aunque estos documentos no muestran un alto grado de especialización (dado que, en ciertos casos, como en el cuartel cuarto, un solo médico debía atender a aproximadamente 25.000 personas, con las más diversas enfermedades), al menos evidencian una vigilancia organizada de la higiene de la comunidad $^{18}$. Por su parte, el número de visitas variaba según la jurisdicción. Sin embargo, su elevada cifra denota la constancia del esfuerzo. En 1901 se realizaron aproximadamente 1.837 visitas en el segundo cuartel, 903 en el tercero y 4.000 en el quinto. Estas consistían en ingresar a los domicilios y hacer un diagnóstico de los afectados y del ambiente, con lo que la labor del médico iba asociada a un minucioso registro de la arquitectura doméstica, donde debían hallarse las causas del mal. Esta asociación entre enfermedad e infraestructura era la piedra angular del conjunto de prácticas conocido como sanitarismo y tuvo un correlato social inmediato: las casas de los ricos difícilmente serían visitadas. Para los especialistas, como el médico del cuartel quinto, existía una

17 Memoria de la Municipalidad de Lima 1901-1903. Las estrategias de intervención médica no se limitaron al espacio urbano, adquiriendo un carácter épico en el ámbito rural. Al respecto, véanse los interesantes relatos sobre las visitas sanitarias consignados en Contreras, 1994, p. 20.

${ }^{18}$ Se trataba de un proceso en ascensión. Si en 1908 existían 517 personas ocupadas en asuntos sanitarios, en 1931 habían llegado a 2.408, lo que significó un aumento absoluto y relativo respecto a la población total de la ciudad (Cueto, 1991, p. 20). 
estrecha vinculación entre "higiene y economía social" y también entre la "calidad de la gente" y las "prácticas de la higiene moderna", como afirmaba su colega del cuartel segundo ${ }^{19}$. Por tanto, la atención se dirigió normalmente a los lugares habitados por el pueblo, sector de la sociedad caracterizado por su "ignorancia (...), malos hábitos y costumbres, y por su mala alimentación"20. La enfermedad se encontraba entre:

“(...) la gente proletaria y en las familias vergonzantes, mujeres en especial, que, obligadas a vivir de su trabajo, mezquinamente remunerado, se alimentan mal y viven en callejones ó en casas de vecindad en las que la vida es imposible a causa de sus malas condiciones higiénicas" 21 .

Por ello, los lugares preferidos de los visitadores eran los callejones $y$ las casas de vecindad ${ }^{22}$. Inscrito en la misma lógica, el médico del cuartel tercero no dudaba en ratificar la referida asociación:

"Al practicar las visitas domiciliarias en el cuartel de mi jurisdicción, me he convencido de que una de las principales causas de la propagación de las enfermedades contagiosas es la aglomeración de individuos de la clase proletaria en los llamados callejones y casas de vecindad" 23 .

Además de los domicilios, debían visitarse otros potenciales epicentros de contaminación (de sífilis, tuberculosis, viruela, etc.) y registrar los posibles agentes, pues el peligro principal residía en la generalización del mal en el recinto urbano, especialmente entre la

${ }^{19}$ Memoria de la Municipalidad de Lima, 1901, pp. XXXV y XXXI.

${ }^{20}$ Ibid., p. XXXV.

${ }^{21}$ Ibid., p. XXIX.

${ }^{22}$ Así, por ejemplo, de las 171 visitas domiciliarias realizadas por el doctor Luis Guillermo Velarde en uno de los cuarteles de la ciudad, 102 fueron a callejones, 43 a casas de vecindad, 15 a tiendas (utilizadas también como habitaciones) y solamente 11 a casas particulares (Memoria de la Municipalidad de Lima, 1903, pp. VIII-IX).

${ }^{23}$ Memoria de la Municipalidad de Lima, 1901, p. XXIX. 
gente decente. Esta preocupación es palpable en el caso de las casas de juego administradas por los chinos que rodeaban el Mercado Central, las que, para el médico del cuartel tercero constituían "verdaderos conservatorios de sifilíticos y de tuberculosos". Esta zona resultaba especialmente peligrosa, considerando que la mayoría de los empleados domésticos que iban al mercado se internaban en sus animados garitos: "Las unas en busca de dinero por el alquiler de su cuerpo, los otros probando fortuna en el juego de la rifa china, y lo que seguramente encuentran es la sífilis o la tuberculosis" 24 . Estas pocilgas eran también espacios ajenos al orden oficial y resultaban peligrosas para la conservación de su estabilidad. En ciertas ocasiones el contagio era aún más nocivo porque algunas enfermedades tenían una connotación social y moralmente peyorativa. Así sucedía con la sífilis, que, según los médicos del servicio urbano, se diferenciaba del resto en la medida en que "repercute en la familia, en la sociedad y en el país" 25 . Por ello era necesario que se brindara especial atención al control de la prostitución, que, según el doctor Pablo Marcial Aguilar, inspector sanitario, sólo se conseguiría "apartando los burdeles a extramuros y dictando una reglamentación para aquellos que se entreguen á esa infame ocupación; así el escándalo será menos pernicioso y notorio"26. Junto con las casas de juego y los prostíbulos, una tercera posibilidad de contagio, bastante preocupante, eran las lavanderas. Se trataba de personas pobres que por lo general lavaban las ropas de los ricos en lugares insalubres y que podían transmitirles sus enfermedades ${ }^{27}$.

Los miembros de la atribulada ciudad oficial habían percibido claramente que resultaba imposible mantenerse ajenos a lo sucedido hasta en el más ínfimo rincón de la urbe, pues podría significar el comienzo de una epidemia. En los tres casos tratados, el principal perjuicio residía en la posibilidad del paso de la dolencia

${ }^{24}$ Ibid., pp. XXVIII-IX.

${ }^{25}$ Ibid., p. XXX.

${ }^{26}$ Memoria de la Municipalidad de Lima, 1889-90, p. 254; original no subrayado.

${ }^{27}$ Memoria de la Municipalidad de Lima, 1901, p. XXIX. 
desde la periferia al centro, del callejón a la mansión. Precisamente las visitas domiciliarias tenían como objetivo llegar hasta el origen del mal, pero de soslayo resultan ofreciendo una perspectiva urbana inédita. En lo referido a la infraestructura de las viviendas populares, lo más notable es que, revisando los informes de 1901 y 1903, redactados por los médicos de los cuarteles, aparece una nueva Lima. La ciudad comenzaba a ser resumida a cifras -evidenciado el influjo de las estadísticas- y los focos infecciosos se encontraban detalladamente localizados gracias al sistema de visitas domiciliarias. Las diversas modalidades de registro confluían para crear el rostro urbano ${ }^{28}$. El detallado inventario, que al mismo tiempo era una instantánea de la ciudad y sugería un programa de acción, servía como base para la mirada más especializada que se estaba constituyendo.

\section{El ALTERADO ESCENARIO}

Las transformaciones en cantidad, composición y distribución de la población limeña durante la segunda mitad del siglo XIX habían quebrado los patrones urbanos tradicionales. En 1906 Lima mostraba un notable crecimiento demográfico. En los últimos 50 años su población prácticamente se había triplicado, albergando entonces más de 140.000 habitantes $^{29}$. Sin embargo, físicamente la ciudad no había cambiado mucho: su sección principal continuaba instalada dentro de los límites coloniales ${ }^{30}$. Esta flagrante contradicción entre una limitada infraestructura y un exceso de ocupantes provocaba la densificación del espacio urbano, manifiesta en la tugurización residencial, especialmente de las viviendas populares $^{31}$. A comienzos de siglo los 671 callejones y 755 casas de vecin-

${ }^{28}$ El notable plano de Lima elaborado por el ingeniero Santiago Basurco (1904), en el que se indicaban las zonas afectadas por la peste bubónica (1903), constituye la cristalización precisa de la confluencia entre el higienismo y el urbanismo y hubiera sido impensable sin las visitas domiciliarias.

${ }^{29}$ Córdova y Urrutia, 1839; Fuentes, 1858; Ministerio de Fomento, 1915.

${ }^{30}$ Cf. Gunther, 1983: planos de Dupard, 1859 y Basurco, 1905.

${ }^{31} \mathrm{El}$ mantenimiento de la ciudad en sus parámetros físicos tradicionales puede explicarse parcialmente por la proliferación de los callejones, que entre 1839 


\section{GABRIEL RAMÓN}

dad repartidos por toda Lima albergaban poco más del $44 \%$ de su población. Debido a su alta representatividad demográfica individual, estos recintos llegaban a constituir pequeños arrabales insertos en medio de la urbe. Así sucedía con la enorme casa del Pescante, casa de vecindad ubicada a sólo una cuadra de la plaza Mayor, que en sus 172 habitaciones alojaba 353 habitantes, y con los tres callejones que conformaban el inmueble de Pueblo Nuevo (distrito $5^{\circ}$ ), con 317 habitaciones. A pesar de las obvias diferencias entre el centro y la periferia de la ciudad, a inicios de siglo aún se mantenía vigente el patrón de barrios indiferenciados, de modo que callejones y casas de vecindad continuaban inmiscuidas entre las residencias de los empleados, profesionales y adinerados ${ }^{32}$. Las viviendas miserables eran una amenaza, incluso físicamente, inmediata para el resto de la ciudad. Los tan temidos "bárbaros" ahora se encontraban intramuros.

La proliferación y subdivisión de estos lugares era la manifestación física de la pauperización urbana. Allí se habían ido aglomerando los ex-esclavos negros, los indios que servían en la ciudad, los chinos compulsivamente importados como mano de obra semiesclava y todos aquellos que necesitaban o eran compelidos a vivir en Lima y carecían de recursos para optar por residencias más holgadas. Esto provocó que, al interior de estos recintos, se mantuvieran modos de vida plenamente distintos a los consagrados por la ciudad oficial. Esta circunstancia, junto con las nuevas intolerancias esgrimidas por la reconstituida elite gobernante, preocupada en "recuperar" una ciudad que se le hacía ajena, sirvió de marco para la entronización de la estrategia de la "sospecha generalizada" que tuvo uno de sus pilares en el higienismo, para el cual los modos de vida privados también influían en la comunidad en general y debían ser fiscalizados. No solamente se trataba de ejercer control hacia el interior de los domicilios, sino, además, de trazar las "murallas interiores" para evitar que los vicios (en el sen-

y 1857 prácticamente duplicaron su número (de 247 a 466), ascendiendo a 471 dos años después (ver Córdova, 1839, Fuentes, 1858 y 1860.

32 Parker, 1995, ha señalado que no era el barrio sino el tipo de domicilio lo que contribuía a marcar el status del habitante. 


\section{EN LOS ARRABALES DE LA CIVILIZACIÓN}

tido médico y social) propios de estos recintos se expandieran por la urbe $^{33}$.

La existencia de espacios ajenos al orden, donde la acción de los patrones se limitaba a la función de administrar, iba en oposición a la utopía sanitarista que las autoridades de la incipiente República Aristocrática pretendían implementar. El proyecto político modernizante, que hasta entonces había apuntado a las modalidades de control del espacio público, ahora dirigía su mirada a los domicilios, antros de origen de las aberraciones privadas y de las calamidades públicas.

\section{Descendiendo al AVERnO}

Surgidas en la intersección de la ideología sanitaria y la política espacial propugnada por la ciudad oficial limeña, las visitas domiciliarias se constituyeron en una de las nuevas modalidades de control estratégico. Uno de sus corolarios fue el literal "descubrimiento" que los representantes de la elite limeña realizaron de los domicilios populares. Como en otras ciudades, la zozobra había provocado una inusitada aproximación de los extremos ${ }^{34}$.

33 El término "sospecha generalizada" pertenece a Sidney Chalhoub, 1996, p.24, que en su libro sobre los cortiços y las epidemias en Rio de Janeiro durante el siglo diecinueve muestra como inmediatamente después de la abolición de la esclavitud tal "teoría" pasó a fundamentar la estrategia de represión de los ex-esclavos fuera de los límites de la unidad productiva. La correlación entre estas modalidades de control y la proliferación de las discusiones sobre el "carácter" de los negros en Rio de Janeiro es un proceso análogo al acaecido en Lima con los indios. Cada nueva forma de administrar a la población miserable debe contar con definiciones que la sustenten.

${ }^{34}$ Se trataba de un incremento de la distancia social que Manuel A. Fuentes y Ricardo Palma habían registrado algunas décadas antes. Lima crecía y las mezclas y choques en su tejido se hacían cada vez más violentos. La constatación del abismo intraurbano y sus peligros llevó a los miembros de la ciudad oficial a visitar territorios desconocidos. Esta práctica, obviamente, comenzó en las ciudades con mayor aglomeración demográfica y se plasmó en forma de informes médicos, investigaciones sociales y novelas "realistas". Apareció así una nueva modalidad narrativa que tenía al cuerpo (o su correspondiente urbano, el domicilio) y sus detalles como objeto de atención directa (Cf. Laqueur, 1995). Aquí se abordará un informe sanitarista propio del género que tiene sus antecedentes europeos en los trabajos del médico inglés 
En el sentido espacial, la estrategia comenzó por el inventario de los lugares potencialmente peligrosos para el resto de la vecindad. En pleno furor de la peste bubónica aparecieron tesis como la titulada La higiene en las casas de vecindad. Necesidad de construir casas higiénicas para obreros (1903), sustentada por Juan Antonio Portella en la Facultad de Medicina de la Universidad de San Marcos para optar al grado de bachiller. Entre sus justificaciones, este trabajo comenzaba señalando el peligro que para la tranquilidad de la ciudad significaban las degradadas condiciones de las viviendas populares, especialmente de sus ocupantes.

"Y algo que también debe tener presente toda persona acomodada es que el pobre en razón de las condiciones miserables de su existencia es un enemigo terrible y un peligro para todos y que hay algo en común á todas las clases y a lo que estamos igualmente expuestos todos: la enfermedad, ésta o más bien el contagio viene a ser como la venganza del desheredado contra la indolencia del rico" 35 .

Seguidamente, el autor sugería que la ciudad oficial debía encargarse de construir casas para los obreros, tanto por razones económicas, morales, como para garantizar su propia subsistencia. Para demostrar las condiciones en que se hallaba este mundo ajeno a la norma, el autor recurre a dos estrategias: presenta fotografías de los lugares visitados (se trata nada menos que de los primeros registros gráficos del "infierno" urbano) y realiza una detallada descripción, para demostrar lo que es la higiene entre esta clase [la "obrera"] voy a describir una de nuestras casas de vecindad, comenzando por una de las más notables que se halla empotrada en el centro mismo de la ciudad. ${ }^{36}$

Con tal propósito, Portella visita y describe dos enormes casas de vecindad localizadas en pleno corazón de la ciudad, la

Edward Chadwick (1842) sobre la pobreza en Londres (Cf. Beguin, 1991). Los antecedentes continentales fueron las investigaciones del doctor G. Rawson (1885) sobre las casas de inquilinato de Buenos Aires.

${ }^{35}$ Portella, 1903 , p. 34.

${ }^{36}$ Portella, 1903, p.15. 


\section{EN LOS ARRABALES DE LA CIVILIZACIÓN}

Casa del Pescante y la Casa de la Columna. Aunque su trayecto fue bastante corto - inclusive deja para otros la descripción de los callejones- esta incursión evidencia una nueva etapa de la policía del espacio urbano: el umbral del domicilio había sido sobrepasado y el ojo de la autoridad operaba desde su interior.

Sin dejar de lado el carácter pionero del trabajo de Portella, donde mejor se plasma la trănsformación táctica es en el detallado informe emitido por la "Comisión nombrada por el gobierno para estudiar las condiciones sanitarias de las casas de vecindad", redactado por dos funcionarios de la recientemente creada sección de Salubridad Pública del Ministerio de Fomento (1907). Dividido en dos secciones, el documento comienza tratando la situación de las viviendas populares y concluye con un proyecto de las futuras casas que debían albergar a este grupo intermedio entre la plebe y el proletariado. Esta detallada instantánea de los escenarios de la infamia urbana fue elaborada por dos representativos personajes de la ciudad oficial, el médico Leonidas Avendaño (1860-1946) y el ingeniero Santiago Basurco (1858-?) $)^{37}$.

Resultándoles logísticamente inviable registrar todas las viviendas populares limeñas, los especialistas seleccionaron poco más de 90 casos. Entre los inmuebles visitados había callejones (66), casas de inquilinato (12), casas mixtas de familia e inquilinato (5), solares (3), numerosas tiendas y algunos pequeños conglomerados urbanos. La gran mayoría de estos recintos se situaba en la periferia, especialmente en el cuartel $3^{\circ}(23)$, en la populosa calle

${ }^{37}$ Avendaño fue un notable médico legista limeño que inmediatamente después de graduarse con la tesis Etiología del tifus exantemático (1883) se dedicó al servicio público. Como jefe de la sección de Identificación y Estadística de la Intendencia de Policía de Lima (1892), introdujo al país los métodos dactiloscópicos y antropométricos de la escuela criminalística italiana. Por su parte, Basurco, luego de iniciar sus estudios universitarios, trabajó como alférez de ingeniería en el Ejército, debiendo abandonar el país luego de la batalla de Miraflores (15/1/1881), que marcó la victoria definitiva de Chile en la Guerra del Pacífico. Graduado como ingeniero en Quito, volvió al Perú, pero emigró inmediatamente a Chile por razones políticas. Al retornar al Perú fue nominado ingeniero de Estado (1897), encargándosele la dirección de edificaciones como la nueva cárcel, el colegio Guadalupe, etc. Realizó también un plano de la ciudad (Milla Batres, 1986). 
de Malambo, en el distrito $9^{\circ}(10)$, y en el distrito $1^{\circ}(15)$. En el sector central (distritos $2^{\circ}$ y $3^{\circ}$ ) sólo se escogieron dos aglomeraciones notables: los alrededores del convento de Santo Domingo y los tugurios adyacentes a la iglesia de San Francisco (mapa 1).

\subsection{LOS DETALLES DE LA INFAMIA}

El relato de Basurco y Avendaño apuntaba hacia dos objetivos. En primer lugar, pretendía superar, y al mismo tiempo reforzar, el efecto de las estadísticas incidiendo en la minuciosa descripción de los casos específicos que resultaran conmovedores. Aunque la representatividad numérica de estas viviendas en la ciudad podía ser un indicador útil, nada mejor que sumergirse a retratar estos lugares:
“(...) cuya existencia parece fantástica, en pleno siglo XX y en una ciudad como Lima (...). Mas que morada de hom- bres civilizados parece cueva de las épocas prehistóricas de los primitivos tiempos de la existencia de la humanidad"38.

En segundo lugar, este registro buscaba sistematizar la información sobre las viviendas populares, dando sustento documental a los miedos que la ciudad oficial abrigaba. No sólo se trataba de saber cuántas personas vivían en cada callejón, sino, además, de conocer el número de cuartos, pisos, cloacas, caños, etc. Para evidenciar el abismo que los separaba de la norma propugnada, el relato destaca ciertas características de los domicilios populares. Primeramente, las grandes dimensiones, la desorganizada complejidad de las habitaciones o viviendas, tales como la casa del Pescante situada en pleno centro de la ciudad, en la parte trasera del convento de Santo Domingo, al que pertenecía. Además de contar con numerosos cuartos y habitantes, ese lugar era:

${ }^{38}$ Basurco y Avendaño, 1907, p. 84. 


\section{EN LOS ARRABALES DE LA CIVILIZACIÓN}

“(...) un maremagnum de pasadizos, escaleras, corredores, sucuchos, un laberinto, en el que como en el de Creta, se necesita el hilo de Ariadna para recorrerlo y salir de ese antro inmundo, negación de toda higiene y escarnio de la civilización en pleno siglo XX" 39 .

La idea de caos, confusión, desorden en vísperas de bullir estaba presente también en la descripción de los callejones de la calle Capón (cuartel $3^{\circ}$ ), que formaban un conjunto de 273 habitaciones con 471 ocupantes:

"A la puerta de calle, grande y amplia, sigue un extenso zaguán con algunos tabiques que lo subdividen en varias secciones, con vericuetos, sucuchos y pasadizos mal pavimentados con piedra rodada. En este primer piso de la casa hay: 5 habitaciones de alquiler, sucias, oscuras y que en lo absoluto carecen de ventilación; puertas que corresponden á las tiendas colindantes; muchos pequeños negocios instalados en el suelo, en banquetas, en un rincón cualquiera $(\ldots)^{\prime 40}$.

Comentarios del mismo tono se encuentran en los párrafos dedicados a los denominados "barrios obreros" o grandes aglomeraciones como Pueblo Nuevo (distrito $5^{\circ}$ ), con un total de 317 cuartos, la callejuela del Pejerrey (distrito $5^{\circ}$ ) o la calle de la Cruz (distrito $6^{\circ}$ ) que incluía 6 callejones, 84 tiendas, una casa de inquilinato $y 759$ habitantes.

Además de las simples dimensiones de las residencias, se trataba de un aspecto cualitativo: las habitaciones populares eran espacios degradados por sus características físicas, donde los servicios eran limitados o inexistentes. Todo comenzaba por la propia infraestructura, pues generalmente habían sido conventos o residencias readaptadas o subdivididas, como la casa de la Columna.

${ }^{39}$ Basurco y Avendaño, 1907, p.48.

${ }^{40}$ Ibid., p.57. 


\section{GABRIEL RAMÓN}

Esta edificación, originalmente claustro del convento de Santo Domingo, había sido sometida a "innovaciones arquitectónicas sin sujección á un plan determinado y sin tener para nada en cuenta las enseñanzas de la higiene". Algo semejante ocurría con los callejones de San Ildefonso, que ocupaban el recinto del antiguo templo del mismo nombre ${ }^{41}$. A esto se agregaba la precariedad de los servicios, principalmente la luz y el agua. Además de carecer de sistemas de iluminación, la desarticulada disposición de las habitaciones y la ausencia de ventanas impedía el ingreso de rayos solares, motivo por el cual incluso al medio día resultaba imposible distinguir los objetos en su interior ${ }^{42}$. Otro elemento problemático eran los servicios higiénicos, que generalmente debían ser compartidos por multitudes, tal como sucedía en el concurrido callejón de Montañón (distrito $1^{\circ}$ ), donde 135 personas utilizaban el mismo caño y la misma cloaca. También era frecuente el uso de las aguas de acequia o servidas para realizar las labores domésticas ${ }^{43}$. Ante la ausencia de luz, agua limpia y aire, las habitaciones se caracterizaban por el hedor, la oscuridad y la humedad ${ }^{44}$.

Toda esta algarabía estructural de las viviendas de la plebe urbana se traducía en la mezcla de funciones y actividades al interior de sus habitaciones, de modo que el lugar destinado al dormitorio servía de cocina y corral simultáneamente, y viceversa. Para Basurco y Avendaño esto podía leerse en la disposición y en las características físicas de los inmuebles:

"Nada más grotezco (sic), más antiestético y más difícil de mantener en buenas condiciones de aseo que el mobiliario que, por lo general, hay en las habitaciones de las casas de vecindad. Muebles de todas las edades y estilos conocidos, recolectados en las casas de compra y venta, desteñidos, desvencijados, con una permanente capa de polvo y mugre, ofrecen aspecto repelente y tipifican la condición moral

\footnotetext{
41 Ibid., pp.50, 62.

42 Ibid., pp. 40, 68.

43 Ibid., pp. 72, 82.

${ }^{44}$ Ibid., p. 30.
} 


\section{EN LOS ARRABALES DE LA CIVILIZACIÓN}

de sus propietarios. Al lado de muebles tapizados para salón, con los muelles flojos y el brocatel desgarrado, se ven humildes silletas de palo, vacilantes porque les falta un pie: veladores sin puertas; cómodas en cuya parte superior no queda sitio disponible, porque todo está ocupado por cuanto cachivache es posible imaginar: perchas sobrecargadas de trajes inmundos, destrozados, trapos sucios: aquello es un pandemonium, una aberración, algo inconcebible (...)"45 .

Hasta entonces las quejas sobre el ornato, fuesen de las autoridades a los particulares o viceversa, se habían limitado al uso del espacio público y de las fachadas de las viviendas. Se podía hacer alusión al mal estado de las cloacas inmediatas a una determinada casa o a la suciedad de su frontispicio. No obstante, críticas como las de Basurco y Avendaño, referidas a aspectos más bien privados, internos, sólo eran concebibles como resultado de la ofensiva sanitarista. La referencia a la disposición del mobiliario se convirtió en una forma de describir a los habitantes, otorgándoles un atributo característico. Consecuentemente, esta mezcla de ambientes y muebles tenía su corolario biológico en la promiscuidad entre personas y animales: "Es costumbre inveterada en los sujetos del bajo pueblo (...) vivir en espantosa promiscuidad con todos los animales domésticos" 46 .

Pero nada mejor que la alusión a los casos extremos para evidenciar la enorme distancia entre las viviendas populares y el orden propugnado por las autoridades. En este asunto destacaban las residencias semisubterráneas, como las grandes casas de inquilinato localizadas al norte del tercer distrito, aledañas al convento de San Francisco, que se encontraban a un nivel inferior al de la calle: "(...) entre los que predomina el (olor) del moho, que ocasiona mareo y hasta vértigo" o el callejón de la calle de la Confianza, que tenía casi la mitad de sus habitaciones a cuatro metros bajo el nivel de la calle ${ }^{47}$. El caso más extremo era el del barrio del

${ }^{45}$ Ibid., p. 109.

${ }^{46}$ Ibid., p. 110. Véase también Ibid., pp. 4, 9, 31, 69.

${ }^{47}$ Ibid., pp. 54, 41. 


\section{GABRIEL RAMÓN}

Cantagallo, "que recuerda las moradas de las antiguas poblaciones nómadas". Localizado en pleno lecho del río Rímac y poblado por 189 personas que vivían en ranchos, este barrio resultaba tan degradante para los higienistas, que no dudaban en calificarlo de "verdaderas cuevas infectas, imposibles hasta para ser habitadas por bestias feroces". Recomendando por ello su desplazamiento, dado que su mera presencia constituía "un peligro para la higiene y la seguridad del vecindario" 48 . Para los especialistas existía una correlación directa entre el espacio doméstico y el carácter de sus habitantes, de modo que las residencias sucias estaban íntimamente asociadas a individuos degradados. Por tanto, estas "cuevas infectas" sólo podían estar ocupadas por personas de tipo semejante:

"Como una prueba de que los moradores de tales tabucos son sujetos que han perdido algo de sentido moral, vale la pena indicar que allí vive un asiático mondonguero, que dedica su tiempo al cuidado de algunas decenas de gatos (no menos de cuatro), en cuya manutención gasta lo que le produce su pequeña industria, viviendo en la miseria y la inmundicia más espantosa" 49 .

\subsection{Los agentes del mal}

Esta asociación entre individuos y residencias era un punto nodal del inventario. Funcionó como justificación de la intervención oficial, en la medida en que una vivienda renovada debía provocar la correspondiente alteración de la conducta de sus habitantes. Sin embargo, la degradación era tal que los miserables que ocupaban estos espacios ni siquiera eran considerados potenciales ciudadanos. Se les trataba como personas de condición física y moralmente infrahumana, virtualmente inertes, como los vecinos del callejón de la Fe, donde había "tantas criaturas, pobremente vestidas, pálidas, tristes y de mirada lánguida, en las que parece que la vida 


\section{EN LOS ARRABALES DE LA CIVILIZACIÓN}

se apaga" ${ }^{50}$. Cosa semejante sucedía en el famoso callejón de Otaiza, poblado de individuos "anémicos, macilentos que tienen las facies típicas de la indolencia y de la molicie" 51 . Pero a esta inercia social se agregaba otro atributo, crucial para los especialistas: la raza. Muchas de las referencias a los vicios genéricos de los pobres, tales como la promiscuidad con los animales o la suciedad, iban acompañadas de una especificación: se trataba de indios. Situados en el estribo de la clasificación social, los indígenas servían como argumento causante y consecuente para explicar la infame situación de los ambientes populares. Al describir la inmundicia reinante en un conglomerado de callejones del quinto distrito, Basurco y Avendaño describían el motivo de su preocupación:

"En todo este conjunto informe de habitaciones viven de preferencia individuos de la raza india, sujetos de temperamento linfático, apocados, pusilánimes, analfabetos y sin asomo de cultura, y como tal sin aptitud ni voluntad alguna para cumplir con los más rudimentales preceptos de la higiene. Así se explica la exagerada insalubridad del barrio descrito, que en el estado en que se encuentra constituye una verdadera amenaza para la población"52.

Horror semejante provocaban los chinos, principalmente situados en los alrededores del mercado Principal (cuartel $3^{\circ}$ ), en especial en el callejón de Otaiza y sus inmediaciones. Las referencias a este grupo estaban asociadas a las enfermedades venéreas, al consumo de opio y tópicos semejantes, tal como lo detallan los especialistas al aludir a la casa de inquilinato conocida como antiguo teatro Odeón, donde había "casa de juego y de prostitución, fumaderos de opio, fondas, pastelerías, peluquerías: una babel, un arrabal chino, en una palabra" 53 . Ante este sórdido cuadro urbano, el principal temor de los higienistas estaba en el contagio que podía dar-

\footnotetext{
50 Ibid., p. 79.

${ }^{51}$ Ibid., p. 57.

52 Ibid., p. 42.

${ }^{53}$ Ibid., p. 58.
} 


\section{GABRIEL RAMÓN}

se de abajo para arriba, de la casa de vecindad al salón elegante. Por eso lo más criticado fue la presencia de recintos inmundos en medio de los barrios más elegantes de la ciudad, tal como sucedía con las señaladas casa del Pescante y casa de la Columna en el distrito segundo o el callejón de la Fe en el distrito séptimo. Esta noción de contagio social se encuentra explícita en el comentario sobre el barrio del callejón de la Cruz, poblado pobre vecino a establecimientos modelo de la elite limeña:

"Urge modificar las malas condiciones del citado barrio, tanto por lo que interesa á sus actuales pobladores como porque en la vecindad están radicados dos establecimientos en que se albergan los hombres del mañana: el colegio de Guadalupe (...) y la Escuela Correccional de Varones" (... $)^{54}$.

En el mismo sentido resultaban preocupantes los agentes de contagio, ciertos individuos que, perteneciendo a la periferia social, prestaban servicios domésticos o íntimos a los privilegiados de la ciudad. Esto permite entender la constante alusión a las lavanderas y a sus condiciones laborales. Al tratar con ropa sucia y agua acumulada, estas mujeres convertían sus habitaciones en "excelente caldo de cultivo para todos los microbios patógenos", de forma que contribuían a infectar sus propias viviendas. Del mismo modo, la infección contenida en la ropa podía trasmitirse a aquellos que la usaban, es decir, a sus clientes del centro de la ciudad ${ }^{55}$.

Sin embargo, en el registro de los higienistas no todo era oprobio e indolencia. Del otro lado de la medalla se encontraban ciertas excepciones, tal como sucedía con el pulcro callejón de la

${ }^{54}$ Ibid., p. 82.

${ }^{55}$ Ibid., pp. 11-2, 39, 43, 47-8. La administración de ciertos servicios ejercidos por las clases populares era un asunto que preocupaba a los "señores" de la urbe ya desde mediados del siglo XIX. Tanto los aguateros, las amas de leche, las lavanderas, las prostitutas, etc. eran potenciales agentes transmisores de enfermedades, por lo cual era imprescindible sustituirlos técnicamente, como sucedió con los primeros que fueron desapareciendo a medida que se instauró el sistema hidráulico en la ciudad, o identificarlos y confinarlos como sucedió con las últimas (Cf. Oliart, 1995). 


\section{EN LOS ARRABALES DE LA CIVILIZACIÓN}

Santa Cueva, alquilado por una señora italiana que, al ejercer "constante y severa vigilancia sobre los vecinos", reproducía a pequeña escala el régimen ideal ${ }^{56}$. Este y otros ejemplos permitían a los higienistas sugerir la posibilidad de cambiar los hábitos de la población a partir del ejemplo y de la mejora de los inmuebles, recurriendo a las reformas parciales. No obstante, en la mayoría de los casos descritos la opción era más severa. Considerados como miembros gangrenados, la única salida era la amputación, por lo cual. resultaba frecuente que el relato descriptivo de un inmueble concluyera recomendando: "con esta casa sólo cabe un remedio: su clausura y demolición inmediata" 57.

\section{Epílogo}

¿Y ahora qué será de nosotros sin bárbaros?

Una solución eran esos hombres. Constantino Cavafis a.1911

5.1 Durante la segunda mitad del siglo XIX, el arrabal se había asentado en el corazón de la civilización. En el regular trazado de las urbes hispanoamericanas comenzaron a ser sistemáticamente identificados los antros del vicio. Su extirpación corrió paralela a la intervención oficial en el espacio privado y la consolidación de la burguesía. En Lima, el escenario político de este trance fue el albor de la República Aristocrática, esa "suerte de síntesis lírica entre una mística popular y una aristocracia de los comportamientos (...). La esquizofrenia entre un discurso ideológico que aún pretendía ser democrático e integrador, unas prácticas económicas que tendían a disgregar a los núcleos sociales que se intentaba unificar y un manejo político autoritario (...)"58. En este prepotente contexto el domicilio del pobre fue concebido como la raíz del mal, cuya potencial difusión hacia palidecer a los nuevos dueños de la urbe.

\footnotetext{
${ }^{56}$ Ibid., p. 60.

57 Ibid., 1907, p. 49.

${ }^{58}$ Mc Evoy, 1997, p. XIII.
} 


\section{GABRIEL RAMÓN}

Para comienzos del siglo XX, 40\% de la población limeña vivía en callejones y casas de vecindad. El primer paso en la higienización de las habitaciones fue la ordenanza municipal (1872) que prohibía la edificación de "balcones cubiertos", que Ricardo Palma consideraba símbolos de la urbe tradicional y Manuel A. Fuentes detestaba como huellas del atraso. Esta disposición pretendía mejorar la ventilación del domicilio y la entrada de luz y de aire en los pisos inferiores. En el mismo año el Reglamento de Policía Municipal señalaba que las habitaciones debían tener como mínimo tres metros cuadrados por cada individuo. En $1884 \mathrm{el} \mathrm{con-}$ cejo municipal promulgó los requisitos a los que estaban sujetas las nuevas construcciones. Así, por ejemplo, para construir el tercer piso de un inmueble era indispensable el informe favorable de los inspectores de obras e higiene. En 1894 otra ordenanza municipal consideraba indispensable la presencia de la autoridad en todos los casos que la "salubridad así lo requería". El inspector de higiene debía visitar todos los recintos destinados a alquiler para constatar que cumplían las normas ${ }^{59}$.

Esta coyuntura de ataque queda documentada en los nuevos usos de la fotografía. Si las primeras reproducciones se habían restringido a los iconos consagrados de Lima, la epopeya sanitarista amplió el radio de acción de este medio, permitiendo el registro de los arrabales de la urbe, la penetración en el infierno. En su conocida tesis, el médico Portella (1903) incluye las primeras fotografías del interior de las residencias populares (de la casa del Pescante y de la casa de la Columna) en las que el "otro" aparece en su propio hogar. Sin embargo, esta aproximación estaba claramente jerarquizada: la privacidad inmaculada de la "familia modelo" contrastaba con la privacidad transgredida de la familia pobre ${ }^{60}$. Las fotos del semanario Variedades testimonian esta distancia. Por un lado eran retratados los elegantes caballeros y damas asistentes a un concierto en el Club Italiano, o los socios del Club Lima, enhiestamente dispuestos alrededor del pabellón nacional ${ }^{61}$. Por

${ }^{59}$ Basurco y Avendaño, 1907, PP. 9-11.

${ }^{60}$ Peluffo, 1996.

${ }^{61}$ Variedades, Lima (22-V-1909, 26-VI-1909). 
el otro, los miserables, los infames, que sólo aparecían cuando osaban cruzarse en el rumbo de la armonía burguesa. Con ocasión del asesinato de una criatura fueron publicadas las fotos de los cinco culpados, reproducciones que, a pesar de su rusticidad, revelaban el alcance de los modernos métodos de registro. Sobre un fondo negro, cada persona aparecía individualmente fotografiada e identificada con un número fijadò en el lado izquierdo del pecho. En el centro de la página, de mayores dimensiones, la foto del sórdido escenario del crimen: un callejón de la calle Yaparióo ${ }^{62}$. Eran estos los iconos de la anti-urbe.

5.2 Circunscrito el espacio público por la red oficial, determinados sus límites y perpetrado el ingreso en los domicilios populares, se trataba de recrearlos. Era el momento de cerrar el círculo instituyendo una modalidad residencial uniformizada, un tipo específico de espacio privado: casitas para los pobres. Sin dejar de lado el "embellecimiento estratégico" a partir de la cirugía externa, se enfatizaba en los interiores, en el hogar como elemento sedentario, el domicilio como pieza fundamental en la estrategia de formación de una mano de obra estable, de las ideologías aseguradoras y de la familia. Sobre estos principios proliferaron los congresos que darían las pautas para las futuras casas populares (París, 1889, 1900; Amberes, 1894; Burdeos, 1894; Bruselas, 1897). Identificada la antítesis urbana, la burguesía imponía su síntesis, el summum de la ortopedia social. En el Perú, los proyectos para construir viviendas populares datan de 1871. En su Proyecto de una sociedad de crédito, Ricardo Monti proponía la creación de una institución destinada a la construcción de residencias para las clases "proletaria y media" 63 . Sin mayor resonancia inmediata, el proyecto de este pionero sólo tuvo seguidores en la primera década del siglo XX, cuando aparecieron muchos trabajos sobre el asunto, redactados por médicos e ingenieros ${ }^{64}$. Insertas en las coorde-

${ }^{62}$ Variedades, Lima (11-VII-1908).

${ }_{63}^{63}$ Mc Evoy, 1997, p. 87

${ }^{64}$ Entre otros, destacan los trabajos de Portella, 1903; Eyzaguirre, 1906, a, b, c, d, León García, 1906; Macedo, 1908; Paulet, 1904, 1909, 1910. 


\section{GABRIEL RAMÓN}

nadas sanitaristas, todas estas propuestas ponían énfasis en la consideración de los domicilios como espacio fundamental de la civilización y en la necesidad de poner en práctica, con adaptaciones locales, las recetas europeas y continentales. Un documento clave de esta coyuntura fue el célebre trabajo de Basurco y Avendaño (1907), cuya segunda parte estaba dedicada a describir en detalle las características de los futuros domicilios populares: a) se especificaban los requisitos para la instalación de las casas de vecindad, b) se clasificaban los tipos de habitaciones obreras europeas, c) se ofrecían los modelos y los detalles de las casas de vecindad a ser instaladas en Lima para los obreros y la "clase pobre" (casa de varios pisos, casa mixta, casa independiente para residencia de una familia, casa individual en la ciudad, hotel para obreros célibes, casa de vecindad con oficinas para trabajar sin salir del domicilio), y d) se señalaban las reformas que debían ser efectuadas para la higienización y mejoramiento de las casas de vecindad existentes. El alcance de la intervención sugerida por estos dos empleados estatales queda claro cuando, al tratar de las funciones de las diversas instituciones en la modificación de las residencias populares, afirman:

\footnotetext{
"Toca á la Municipalidad intervenir en cuanto se relaciona con la estética y la higiene de la población y de sus moradores y es tan vasto su campo de acción á este respecto, que su autoridad debe dejarse sentir no sólo en la red urbana, calles y fachadas de las casas, sino también en su arreglo interior hasta en sus más mínimos detalles ${ }^{65}$.
}

Bajo este signo, desde la primera década de este siglo comenzaron a aparecer en Lima las viviendas obreras colectivas ${ }^{66}$. 


\section{Bibliografía}

ARCHILA, Ricardo

1983 "La medicina y la higiene en la ciudad", en Francisco Solano (Comp.), Estudios sobre la ciudad iberoamericana, C.S.I.C., Madrid, pp. 655-685.

AGUIRRE, Carlos

1995 "La penitenciaria de Lima y la modernización de la justicia penal en el siglo XIX", en Panfichi y Portocarreo, pp. 343-372.

BARRÁN, José

1994 Medicina y sociedad en el Uruguay del novecientos (T. II: La ortopedia de los pobres), Ediciones de la Banda Oriental, Montevideo.

Barrán, José, Gerardo Caetano Teresa Porzecanski

1996 Historia de la vida privada en el Uruguay (T. II: El nacimiento de la intimidad: 1870-1920), Ed. Santillana, Montevideo.

BASURCo, Santiago y Leonidas Avendaño

1907 "Informe emitido por la comisión nombrada por el gobierno para estudiar las condiciones sanitarias de las casas 
de vecindad", en Boletín del Ministerio de Fomento, Dirección de Salubridad Pública, III/4-5 Lima.

Beguin, François

1991 "As maquinarias inglesas do conforto", en Espaço e Debate 34, N.E.R.U., São Paulo, pp. 39-54.

Chalmoub, Sidney

1996 A cidade febril. Cortiços e epidemias na Corte Imperial, Companhia das Letras, São Paulo.

CiPOLA, Carlo

1993 Contra un enemigo mortal e invisible, Ed. Crítica, Barcelona.

Clement, Jean-Pierre

1983 "El nacimiento de la higiene urbana en la América española del siglo XVIII", en Revista de Indias LIII/171, CSIC, Madrid, pp. 77-95.

Contreras, Carlos

1994 Sobre los orígenes de la explosión demográfica en el Perú (1876-1940), IEP, Lima.

CóRdova y URRUTia, José María

1839 Estadística histórica, geográfica, industrial y comercial de los pueblos que componen las provincias del departamento de Lima, Imp. de Instrucción Pública, Lima

Cueto, Marcos

1991 "La ciudad y las ratas: la peste bubónica en Lima y en la costa peruana a comienzos del siglo XX", en Histórica XV/1, PUCP, Lima, pp. 1-26.

EYZAGUIRRE, Rómulo

$1906^{a}$ "Demografía sanitaria. Enfermedades evitables", en Boletín del Ministerio de Fomento II/1, Dirección de Salubridad Pública, Lima. 


\section{EN LOS ARRABALES DE LA CIVILIZACIÓN}

1906b "Influencia de las habitaciones de Lima sobre las causas de su mortalidad", en Boletín del Ministerio de Fomento II/1, Dirección de Salubridad Pública, Lima.

1906c "Valor económico de la vida humana", en Boletín del Ministerio de Fomento II/1, Dirección de Salubridad Pública, Lima.

1906d "Las epidemias amarílicas de Lima", en Boletín del Ministerio de Fomento II/8, Dirección de Salubridad Pública, Lima.

FUENTES, Manuel

1858 Estadística general de Lima, Tipografía Nacional de M.N. Corpancho por J.H. del Campo, Lima.

1860 Guía histórico descriptiva administrativa, judicial y de domicilio de Lima, Librería central, Lima.

GUNTHER, Juan

1983 Planos de Lima: 1613-1983, Municipalidad de Lima y PetroPerú, Lima.

LEÓN GARCÍA, Enrique

1906 "Alojamiento para la clase obrera en el Perú", en Boletín del Ministerio de Fomento II/1, - Dirección de Salubridad Pública, Lima.

GuTIÉRREZ, Ramón

1983 Arquitectura y urbanismo en Iberoamérica, Ed. Cátedra, Madrid.

HERNÁNDEZ, Regina (Edt.)

1994 La ciudad de México en la primera mitad del siglo XIX (2 Vol.), Instituto Mora, México.

Huamán María y Ruiz Manuel

1990 Las casas obreras de la Sociedad de Beneficencia Pública de Lima. Obra de Rafael Marquina (tesis de bachillerato), UNI, Lima. 


\section{GABRIEL RAMÓN}

Laqueur, Thomas

1995 "Corpos, detalhes e a narrativa humanitária", en A nova história cultural, Lynn Hunt ed. Martin Fontes, São Paulo, pp. 239-277.

LASTRES, Juan

1951 Historia de la medicina peruana (T. III: La medicina en la república), UNMSM, Lima.

LeÓN GarCía, Enrique

1906 "Alojamiento para la clase obrera en el Perú", en Boletín del Ministerio de Fomento II/1, Dirección de Salubridad Pública, Lima.

MACEDO, J.M.

1908 "Casas de vecindad para la clase menesterosa", en Boletín del Ministerio de Fomento II/3, Dirección de Salubrịdad Pública, Lima.

Majluf, Natalia

1994 Escultura y espacio público (Lima: 1850-1879), IEP, Lima.

Mc Evor, Carmen

1997 La utopía republicana. Ideales y realidades: formación de la cultura política peruana (1871-1919), PUCP, Lima.

MÉNDEZ, Cecilia

1987 "Penalidad y muerte en el Perú", en Márgenes, año I, No 1, Lima, pp. 182-191.

Mila Batres, Carlos (Edt.)

1986 Diccionario histórico y biográfico del Perú, Milla Batres, Lima.

Ollart, Patricia

1995 "Poniendo a cada uno en su lugar: estereotipos raciales y sexuales en la Lima del siglo XIX", en Panfichi y Portocarrero, pp. 261-288. 
PANFICHI, Aldo y Felipe Portocarrero (Edts.)

1995 Mundos Interiores: Lima 1850-1950, Universidad del Pacífico, Lima.

PARKER, David

1995 "Los pobres de la clase media: estilo de vida, consumo e identidad en una cultura tradicional", en Panfichi y Portocarrero, pp. 161-185.

Paulet, Pedro

1904 "Las habitaciones baratas", en Boletín Oficial de Fomento y Obras Públicas, Ministerio de Fomento, Lima, pp. 69108.

1909 "Construcción de habitaciones para obreros", en Boletín Oficial de Fomento y Obras Públicas, Ministerio de Fomento, Lima, pp. 49-71.

1910 "Habitaciones baratas", en Boletín Oficial de Fomento y Obras Públicas, Ministerio de Fomento, Lima, pp. 2643.

PeLuffo, Gabriel

1996 "Construcción y crisis de la privacidad en la iconografía del novecientos", en Barrán, Gaetano y Porzecanski, pp. 57-73.

Portella, Juan Antonio

1903 La higiene de las casas de vecindad. Necesidad de construir casas higiénicas para obreros (tesis de bachillerato), UNMSM, Lima.

RAMÓN (de), Armando

1992 Santiago de Chile, Ed. Mapfre, Madrid.

RAMÓN, Gabriel

1997 "Con la patria en las paredes", en Contracorriente 1, pp. 85-104, Lima. 


\section{GABRIEL RAMÓN}

ROMERO, José L.

1976 Latinoamérica, las ciudades y las ideas, Ed. Siglo XXI, Buenos Aires.

Ruiz, Augusto

1994 Psiquiatras y locos. Entre la modernización contra los Andes y el nuevo proyecto de modernidad. Perú: 18501930, Instítuto Pasado y Presente, Lima.

SIN AUTOR

1889-1903 Memoria de la municipalidad de Lima, Ed. Gil, Lima. 